\title{
IMPLEMENTASI KOMBINASI MEDIA KOMUNIKASI ONLINE DALAM PENDIDIKAN GIZI PRAKONSEPSI GENERASI MILENIAL
}

\author{
Yusnia Nur Aziizah, Choirul Anna Nur Afifah \\ (Universitas Negeri Surabaya)
}

\begin{abstract}
Preconception nutrition education is one of the iefforts to prepare the millennial generation to face marriage and produce healthy and quality offspring. The characteristics of millennial generation who understand information technology and the occurrence of a pandemic are the reasons to use online communication media in nutrition education. This study aims to determine the most effective combination of online communication media (Microsoft SwayWhatsapp and Microsoft Sway-Zoom Cloud Meeting) used in preconception nutrition education for the millennial generation. The study used a quasi-experimental method with a nonequivalent control group pre-test and post-test design. Samples of 60 people obtained by the purposive sampling technique. Quantitative data on nutritional knowledge between groups were analyzed by independent $t$-test. Research shows that using a combination of online communication media can effectively improve educational outcomes. There is no significant difference in the results of millennial nutrition education in the use of the two combinations of online communication media, but the use of the Microsoft Sway-Whatsapp combination is considered to give better results because it is considered practical, easy to use, and does not require more quota pulses. The use of online communication media in education is necessary. considering media capabilities, internet network, and access costs for optimally goals.
\end{abstract}

Keywords: Preconception Nutrition; Millennial Generation; Online Communication Media; Education

\begin{abstract}
Abstrak
Pendidikan gizi prakonsepsi merupakan salah satu upaya penting mempersiapkan generasi milenial menghadapi pernikahan dan memperoleh keturunan yang sehat serta berkualitas. Karakeristik generasi milenial yang paham teknologi informasi dan terjadinya pandemi menjadi alasan perlunya pemanfaatan media komunikasi online dalam pendidikan gizi. Penelitian ini bertujuan untuk mengetahui kombinasi media komunikasi online (Microsoft Sway-Whatsapp dan Microsoft Sway-Zoom Cloud Meeting) yang paling efektif digunakan dalam pendidikan gizi prakonsepsi generasi milenial. Penelitian menggunakan metode Quasi Eksperimen dengan rancangan pre-test and post-test nonequivalent control group. Jumlah sampel 60 orang yang diperoleh dengan teknik Purposive Sampling. Data kuantitatif pengetahuan gizi antar kelompok dianalisis dengan Independent t-test. Penelitian menunjukkan penggunaan kombinasi media komunikasi online secara efektif dapat meningkatkan hasil pendidikan. Tidak terdapat perbedaan signifikan hasil pendidikan gizi generasi milenial pada penggunaan kedua kombinasi media komunikasi online, namun penggunaan kombinasi Microsoft Sway-Whatsapp dinilai memberikan hasil yang lebih baik karena dinilai praktis, mudah digunakan dan tidak membutuhkan lebih banyak pulsa kuota Penggunaan media komunikasi online dalam pendidikan sebaiknya mempertimbangkan kemampuan media, jaringan internet, dan biaya akses agar tujuan tecapai secara optimal.
\end{abstract}

Kata Kunci: Gizi Prakonsepsi; Generasi Milenial; Media Komunikasi Online; Pendidikan 


\section{PENDAHULUAN}

Generasi milenial merupakan generasi yang lahir pada tahun 1980 - 2000. Generasi milenial hidup pada perkembangan teknologi yang pesat, kurang suka membaca secara konvensional, lebih percaya informasi interaktif daripada searah dan lebih memahami teknologi dibandingkan orangtua ${ }^{1}$. Berdasarkan tahun kelahiran, rentang usia generasi milenial saat ini adalah 16-30 tahun yang merupakan rentang usia produktif dan puncak reproduksi sehingga berdasarkan usia dan karakteristik tersebut generasi milenial dianggap siap untuk menikah. Presentase generasi milenial yang belum kawin $(58,42 \%)$, berstatus kawin $(40,12 \%)$. Presentase generasi milenial perempuan yang berstatus kawin lebih banyak hampir dua kali lipat dibandingkan dengan laki-laki $(51,64 \%)$. Sebagian besar menikah pada usia antara 19-24 tahun.

Perkawinan merupakan salah satu cara untuk memperoleh keturunan. Kualitas keturunan atau generasi tidak hanya ditentukan oleh status gizi ibu pada masa $1000 \mathrm{HPK}$ namun juga pada periode prakonsepsi. Kesehatan prakonsepsi terutama status gizi menjadi sangat penting untuk diperhatikan dalam upaya mempersiapkan kehamilan ${ }^{2}$. Beberapa masalah gizi seringkali terjadi pada periode prakonsepsi dan hal ini dapat berdampak pada kondisi kehamilan dan kesehatan bayi yang dilahirkan nantinya.

KEK (Kurang Energi Kronis) merupakan masalah gizi yang biasa terjadi pada wanita usia subur. Resiko bagi wanita yang mengalami KEK diantaranya anemia, bayi BBLR (Berat Badan Lahir Rendah) lahir prematur atau cacat dan dapat berdampak pada kematian ibu dan bayi. KEK dan anemia pada kehamilan merupakan penyebab tingginya Angka Kematian Ibu (AKI). Kota Surabaya menjadi penyumbang Angka Kematian Ibu (AKI) terbesar di Provinsi Jawa Timur. Pada tahun 2017 Angka Kematian Ibu mencapai 79,40 per 100.000 kelahiran hidup atau 34 jiwa kematian ibu dan menjadikan kota Surabaya di urutan kedua penyumbang AKI pada tahun $2017^{3}$.

Pengaturan gizi yang baik akan bermanfaat untuk membentuk sel telur dan sel sperma yang baik sehingga menghasilkan proses pembuahan yang berkualitas. Status gizi dipengaruhi oleh pemilihan makanan seseorang berdasarkan pengetahuan atau pengalaman yang dimiliki. Sehingga perlu adanya upaya untuk meningkatkan pengetahuan gizi prakonsepsi pada generasi milenial terutama wanita usia subur sebagai bekal agar dapat menjaga kehamilan sejak dini dengan pengaturan gizi yang baik. Strategi untuk meningkatkan pengetahuan adalah melalui pendidikan. Pendidikan gizi merupakan upaya untuk dapat meningkatan pengetahuan dan perubahan sikap ${ }^{4}$.

Pendidikan gizi prakonsepsi merupakan salah satu upaya meningkatkan pengetahuan yang nantinya dapat berpengaruh pada pemilihan makanan dan status gizi seseorang sebelum menikah yang nantinya dapat berpengaruh pada kualitas dan kesehatan bayi yang dilahirkan. Perkembangan teknologi yang pesat dan masa pandemi covid-19 yang 
membatasi kegiatan pendidikan tatap muka secara langsung, maka pendidikan secara online atau daring seringkali menjadi alternatif, dengan menggunakan media komunikasi online kegiatan pendidikan dapat berlangsung walapun ditempat yang berbeda, dapat mengirim pesan teks, gambar, panggilan audio serta melakukan video conference. Media komunikasi online yang saat ini seringkali digunakan untuk pendidikan di masa pandemi Covid-19 diantaranya Whatsapp, Zoom Cloud Meeting dan Microsoft Sway.

Microsoft Sway adalah program presentasi berbasis web yang biasa digunakan untuk membuat materi pelajaran agar lebih menarik dan interaktif. Dalam media ini dapat ditambahkan teks, gambar, dokumen, video, grafik, atau animasi lainnya konten ${ }^{5}$. Berdasarkan hasil penelitian yang dilakukan di SMP Negeri 3 Probolinggo, pengembangan media pembelajaran berbasis Sway memudahkan peserta didik untuk memahami materi ${ }^{6}$. Penelitian lain menungkapkan penggunaan aplikasi Microsoft Sway mampu meningkatkan kemampuan kolaborasi pada mahasiswa ${ }^{7}$. Kekurangan dari Microsoft Sway adalah perlu adanya koneksi internet untuk mengakses laman dan keterbatasan pengguna untuk berkreasi karena desain sudah tersedia. Microsoft Sway dapat digunakan sebagai alternatif media penyampaian materi selain power point dan handout. Materi pada Microsoft Sway dapat disampaikan melalui media komunikasi Online yaitu Whatsapp atau Zoom Cloud Meeting.

Whatsapp adalah aplikasi perpesanan instan seluler gratis dan telah digunakan oleh satu milyar orang di sekitar dunia di lebih dari 180 negara $^{8}$. Keberadaan WhatsApp memudahkan kegiatan komunikasi baik jarak dekat maupun jarak jauh, lisan atau tulisan dan mampu menyimpan pesan dan sangat praktis ${ }^{9}$. Terdapat banyak fitur dalam Whatsapp diantarnya untuk berkirim pesan secara instan, bertukar gambar, video, foto, pesan suara, berbagi informasi dan diskusi ${ }^{10}$. Berbagai macam fitur Whatsapp memiliki manfaat yang cukup besar dalam pembelajaran. Berdaarkan hasil penelitian penggunaan Whatsapp dalam kegiatan pendidikan memiliki dampak pada kegiatan pendidikan mahasiswa dalam menciptakan suasana akademis yang kondusif dan fleksibel ${ }^{11}$. Penelitian lain juga menunjukkan bahwa Whatsapp memiliki potensi untuk kegiatan pembelajaran dimanapun secara kolaboratif dan dapat meningkatkan interaktivitas sosial siswa ${ }^{12}$. Selain kelebihan yang dimiliki Whatsapp juga memiliki kekurangan, penggunaan Whatsapp sebagai media pembelajaran daring dianggap kurang efektif karena penjelasan melalui pesan grup yang kurang komprehensif dan jarang memperoleh video penjelasan yang dapat memberikan pemahaman lebih baik dibandingkan memberikan soal latihan ${ }^{13}$.

Zoom Cloud Meeting adalah aplikasi untuk melakukan video conference yang biasa digunakan dalam kegiatan pendidikan dapat digunakan dalam beranggotakan jumlah besar, aplikasi ini juga memungkinkan penggunanya untuk mengirim pesan teks dan melakukan presentasi secara langsung. Kegiatan pendidikan secara online menggunakan aplikasi 
Zoom Cloud Meeting sama seperti proses belajar tatap muka di kelas bahkan memiliki kelebihan yaitu proses pembelajaran yang menjadi lebih santai daripada tatap muka secara langsung ${ }^{14}$. Kekurangan Zoom Cloud Meeting diantaranya terkait koneksi internet yang buruk, keterbatasan kamera dan microphone yang berpengaruh pada kualitas video/audio, koneksi panggilan terputus, atau keterlambatan sehingga menjadi penghambat dalam komunikasi selain itu Zoom Cloud Meeting tidak memiliki fitur keamanan end to end sehingga data tidak mampu terlindungi secara maksimal ${ }^{15}$.

Pendidikan gizi prakonsepsi merupakan salah satu upaya penting mempersiapkan generasi milenial menghadapi pernikahan dan memperoleh keturunan yang sehat serta berkualitas. Karakeristik generasi milenial yang paham teknologi informasi dan terjadinya pandemi menjadi alasan perlunya pemanfaatan media komunikasi online dalam pendidikan gizi. Pemanfaatan media pada dasarnya bertujuan untuk membantu dalam efektifitas dan efisiensi kegiatan pendidikan ${ }^{16}$. Penelitian ini bertujuan untuk mengetahui kombinasi media komunikasi online (Microsoft Sway-Whatsapp dan Microsoft Sway-Zoom Cloud Meeting) yang paling efektif digunakan dalam pendidikan gizi prakonsepsi generasi milenial.

\section{METODE PENELITIAN}

Metode Penelitian ini menggunakan desain eksperimen semu (Quasi Experiment) dengan rancangan pre-test and post-test nonequivalent control group. Penentuan Kelompok eksperimen dan kontrol tidak dipilih secara acak. Kelompok eksperimen menggunakan media kombinasi Microsoft Sway-Zoom Cloud Meeting sementara kelompok kontrol sebagai pembanding menggunakan media kombinasi Microsoft Sway-Whatsapp.

\section{Responden Penelitian}

Responden penelitian diperoleh dengan teknik purposive sampling secara online melalui publikasi poster rekrutmen responden. Menurut Notoatmodjo sebelum pengambilan sampel perlu ditentukan krtieria inklusi. Pada penelitian ini ditentukan kriteria inklusi sebagai berikut:

1. Remaja akhir perempuan umur (17-25 tahun)

2. Belum menikah, domisili Surabaya

3. Memiliki laptop/hp pribadi, mengenal Zoom Cloud Meeting dan Whatsapp

4. Bersedia menjadi responden penelitian.

Jumlah sampel ditentukan menggunakan rumus analitik komparatif numerik berpasangan ${ }^{17}$. Sejalan dengan penelitian yang dilakukan oleh Perdana diketahui:

$$
\begin{aligned}
& n=\left(\frac{(Z \alpha+Z \beta) S}{X 1-X 2}\right)^{2}=\left(\frac{(1,96+1,036) 9}{5}\right)^{2} \\
& n=29,08 \approx 30 \text { orang/kelompok }
\end{aligned}
$$

Jumlah ini ditetapkan pada setiap kelompok kontrol dan eksperimen sehingga total keseluruhan sampel 60 orang. 


\section{Data dan Teknik Pengumpulan Data}

Data primer penelitian yang dikumpulkan adalah data karakteristik generasi milenial dan data hasil pendidikan gizi. Data karakteristik responden meliputi: umur, tingkat pendidikan, durasi penggunaan internet, sumber akses informasi gizi yang diisi secara langsung oleh responden melalui kuisioner online. Sedangkan data hasil pendidikan gizi prakonsepsi diperoleh melalui tes sebelum (pretest) dan sesudah (posttest) pendidikan gizi tentang materi pengertian dan pemenuhan gizi prakonsepsi, masalah gizi pada periode prakonsepsi dan strategi mencegah masalah gizi prakonsepsi. Instrumen yang digunakan adalah tes online yang dibuat menggunakan aplikasi FormApp, berisi 20 butir soal terkait gizi prakonsepsi dengan bobot tiap soal 5 poin.

\section{Analisis Data}

Data karakteristik generasi milenial dianalisis secara univariat dan disajikan dalam bentuk tabel dan narasi. Data hasil pendidikan gizi dilakukan uji normalitas terlebih dahulu dengan Kolmogorov Smirnov dan diperoleh hasil data kedua kelompok berdistribusi normal dengan nilai signifikan $\leq 0,05$. Hasil pendidikan gizi berupa skor pretest-postest tiap kelompok dianalisis dengan uji Paired Sample t-test. Uji Independent t-test untuk mengetahui perbedaan penggunaan kombinasi media antara kelompok kontrol dan kelompok eksperimen. Penelitian dilakukan secara online pada bulan Februari-April 2021. Kegiatan penelitian ini telah mendapatkan persetujuan dari komite etik Universitas Airlangga Faculty of Dental Medicine No.550/HRECC.FODM/XII/2020.

\section{HASIL PENELITIAN \\ Karakteristik Responden}

Karakteristik responden yang meliputi umur, tingkat pendidikan, frekuensi penggunaan internet dan sumber informasi gizi cukup bervariasi Distribusi karakteristik responden dapat dilihat pada Tabel 1.

Tabel 1. Distribusi Karakteristik Responden

\begin{tabular}{llccc}
\hline \multirow{2}{*}{ Variabel } & \multirow{2}{*}{ Kategori } & \multicolumn{2}{c}{ Jumlah } \\
\cline { 3 - 4 } Umur & 17 tahun & $\mathrm{f}$ & $\%$ \\
(Remaja Akhir) & 19 tahun & 3 & 5 \\
& 20 tahun & 7 & 11.7 \\
& 21 tahun & 14 & 23.3 \\
& 22 tahun & 22 & 36.7 \\
& 23 tahun & 9 & 15 \\
& 24 tahun & 3 & 5 \\
& 25 tahun & 1 & 1.7 \\
\hline Tingkat & SMA & 1 & 1.7 \\
Pendidikan & S1/D3/D4 & 46 & 76.7 \\
\hline Frekuensi & 1 s/d 3 jam/hari & 14 & 23.3 \\
Penggunaan & 4 s/d 7 jam/hari & 7 & 11.7 \\
Internet & $>$ 7 jam/hari & 22 & 36.7 \\
\hline
\end{tabular}




\begin{tabular}{llcc}
\hline Sumber & Buku | Internet/Hp & \\
Informasi Gizi & Tv | Internet/Hp | Teman & 3 & 5 \\
& Tv | Internet/Hp | Guru & 2 & 3.3 \\
& Buku | Internet/Hp | Guru | Teman & 4 & 6.7 \\
Internet/Hp & 12 & 20 \\
Buku | Tv | Radio | Internet/Hp | Orangtua | & 17 & 28.3 \\
Teman & 6 & 10 \\
Buku | Guru | Teman & 1 & 1.7 \\
Buku | Tv | Internet/Hp | Guru | Teman & 1 & 1.7 \\
Internet/Hp | Teman & 4 & 6.7 \\
Buku | Tv | Internet/Hp & 2 & 3.3 \\
Buku & 1 & 1.7 \\
Internet/Hp | Orangtua & 3 & 5 \\
Tv | Internet/Hp | Guru | Teman & 1 & 1.7 \\
Tv | Internet/Hp | Orangtua & 1 & 1.7 \\
Radio | Internet/Hp | Orangtua | Guru | & 1 & 1.7 \\
Teman & 1 & 1.7 \\
Tv | Internet/Hp & & \\
\hline
\end{tabular}

Sumber: Data Primer

Umur responden berkisar antara 17-25 tahun dengan tingkat pendidikan generasi milenial mayoritas pendidikan terakhir SMA. Mayoritas responden menggunakan internet dan media sosial generasi milenial dengan durasi $>7$ jam/hari. Sumber akses informasi gizi yang digunakan mayoritas berasal dari internet/Hp dan sedikit yang menggunakan buku.

\section{Pengetahuan Gizi Prakonsepsi Generasi Milenial}

Pengetahuan gizi prakonsepsi diukur berdasarkan hasil skor pretest dan postest dari kegiatan pendidikan gizi kelompok kontrol yang menggunakan media kombinasi Microsoft Sway- Whatsapp dan kelompok eksperimen yang menggunakan Microsoft Sway-Zoom Cloud Meeting. Skor yang diperoleh dianalisis dengan Paired Sample t-test. Hasil terdapat pada Gambar 1.

A. Rata-Rata Hasil Pendidikan Gizi Prakonsepsi Berdasarkan Skor Pretest-Postest

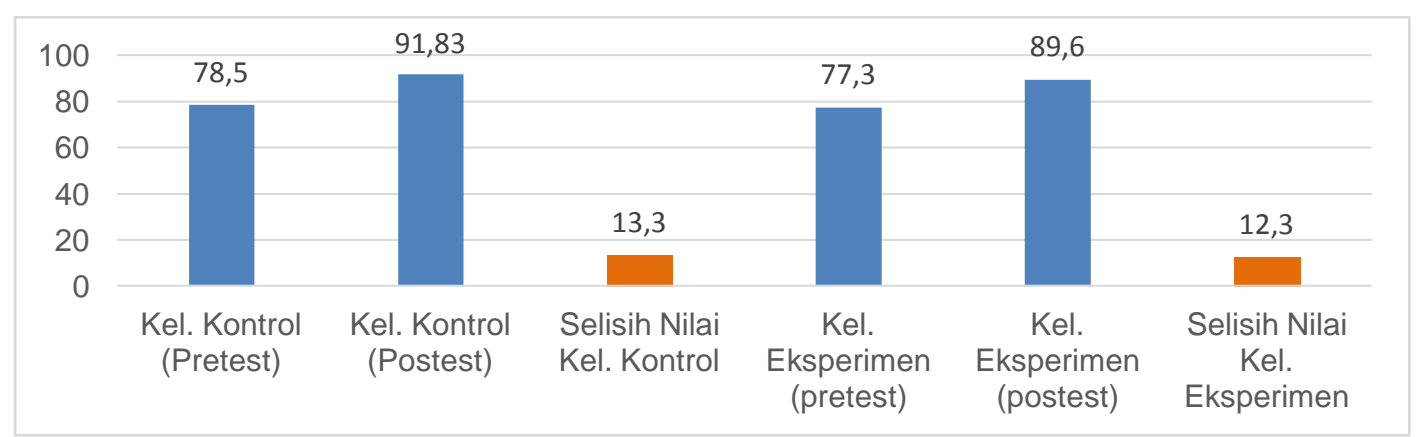

\section{Gambar 1. Rata-Rata Skor Pretest dan Postest}

Sumber: Data Primer

Berdasarkan Gambar 1 diketahui terdapat peningkatan hasil skor pretest dan postest pada kedua kelompok yaitu kelompok kontrol yang menggunakan media Whatsapp dan kelompok eksperimen yang menggunakan media Zoom Cloud Meeting berdasarkan hasil 
tersebut dapat diartikan bahwa penggunaan media Zoom Cloud Meeting dan Whatsapp sama-sama memberikan pengaruh terhadap peningkatan hasil pendidikan gizi prakonsepsi generasi milenial. Namun berdasarkan selisih nilai pretest dan postest diperoleh kelompok kontrol memiliki selisih nilai yang lebih tinggi $(13,3)$ dibandingkan dengan kelompok eksperimen $(12,3)$ hal ini diartikan bahwa penggunaan media Whatsapp memiliki pengaruh yang lebih baik dalam peningkatan hasil pendidikan gizi prakonsepsi dibandingkan dengan Zoom Cloud Meeting.

\section{B. Tingkat Perbedaan Rata-Rata Skor Pengetahuan Pretest dan Postest}

Perbedaan rata-rata nilai kelompok pre-test dan post-test dianalisis dengan paired sample $t$-test dan hasil disajikan pada Tabel 2

Tabel 2. Hasil Uji Perbedaan Rata-Rata dengan Paired Sample t-test

\begin{tabular}{lccccc}
\hline \multirow{2}{*}{ Kelompok } & \multirow{2}{*}{$\mathrm{n}$} & p-value & $\mathrm{T}$ & \multicolumn{2}{c}{$95 \% \mathrm{Cl}$} \\
\cline { 5 - 6 } & & & & Lower & Upper \\
\hline Kelompok Kontrol & 30 & 0,000 & $-7,282$ & $-17,07$ & $-9,58$ \\
\hline Kelompok Eksperimen & 30 & 0,000 & $-7,256$ & $-15,68$ & $-8,98$ \\
\hline
\end{tabular}

Sumber: Data Primer

Berdasarkan tabel diatas diketahui nilai $t_{\text {hitung }}$ pada kelompok kontrol sebesar -7,282 dengan nilai signifikansi $p=0,000$. Dari hasil tersebut diketahui nilai signifikan $<0,05$ Sehingga hasil tersebut dapat dinyatakan bahwa terdapat perbedaan yang signifikan hasil pendidikan gizi sebelum dan sesudah pada kelompok kontrol yang menggunakan kombinasi media komunikasi online Whatsapp dan Microsoft Sway. Pada Kelompok eksperimen nilai $t_{\text {hitung }}$ sebesar $-7,526$ dengan nilai signifikansi $p=0,000$. Dari hasil tersebut diketahui nilai signifikan $<0,05$ Sehingga hasil tersebut dapat dinyatakan bahwa terdapat perbedaan yang signifikan hasil pendidikan gizi sebelum dan sesudah pada kelompok eksperimen yang menggunakan kombinasi media komunikasi online Zoom Cloud Meeting dan Microsoft Sway.

\section{Pengaruh Penggunaan Kombinasi Media Komunikasi Online Terhadap Hasil Pendidikan Gizi Prakonsepsi}

Hasil pendidikan gizi prakonsepsi berupa selisih nilai pretest dan postest pada kelompok eksperimen dan kelompok kontrol dilakukan uji Independent sample t-test untuk mengetahui perbedaan pengaruh penggunaan kombinasi media komunikasi online antara kelompok kontrol dan kelompok eksperimen terhadap hasil pendidikan gizi prakonsepsi. Hasil uji Independent Sample t-test disajikan pada Tabel 3.

\section{Tabel 3. Hasil Uji Perbedaan Pengaruh dengan Independent Sample T-Test}




\begin{tabular}{lllll}
\hline Kelompok & N & p-value & 95\% Cl & \\
\cline { 4 - 5 } & & & Lower & Upper \\
$\begin{array}{l}\text { Kksperimen dan } \\
\text { Kontrol }\end{array}$ & 60 & 0,686 & $-8,64$ & 4,31 \\
\hline $\begin{array}{l}\text { Sumber: Data Primer } \\
\text { Sumbry }\end{array}$ & & & &
\end{tabular}

Berdasarkan hasil analisis selisih nilai dengan Independent $t$-test diperoleh nilai $p$ yaitu 0,686 > 0,05, maka dapat diartikan bahwa tidak terdapat perbedaan yang signifikan hasil pendidikan gizi prakonsepsi antara kelompok eksperimen yang menggunakan Zoom Cloud Meeting-Microsoft Sway dan kelompok kontrol yang menggunakan WhatsappMicrosoft Sway.

\section{PEMBAHASAN}

\section{Karakteristik Generasi Milenial}

Berdasarkan hasil pengumpulan data karakteristik generasi milenial. Semua responden yang mengikuti kegiatan penelitian berstatus belum menikah dan termasuk dalam rentang umur remaja akhir. Generasi milenial adalah generasi yang lahir pada tahun 1981-2000 atau saat ini berusia 15- 34 tahun'1. Menurut Badan Pusat Statistik 2017 rata-rata generasi milenial perempuan menikah pada usia 20-21 tahun ${ }^{18}$ Namun pada penelitian ini sebagian besar usia 20-21 tahun generasi milenial di Surabaya masih belum menikah.

Faktor usia dapat dapat menjadi indikator dalam memahami karakteristik peserta didik yang kemudian akan berpengaruh pada pemilihan strategi pendidikan yang dilakukan. Strategi Pendidikan yang digunakan terhadap usia remaja atau dewasa tentu berbeda dengan pendekatan belajar yang digunakan terhadap anak-anak ${ }^{19}$. Semakin bertambahnya usia maka tingkat kemampuan dalam berpikir dan daya tangkap juga semakin baik yang nantinya akan berpengaruh pada pengetahuan yang dimiliki. Menurut penelitian pada usia 20-35 tahun, individu akan lebih banyak menggunakan waktu untuk membaca sebagai upaya penyesuaian diri di usia tua ${ }^{20}$. Rentang usia ini tergolong dalam generasi milenial yang memiliki rasa ingin tahu yang tinggi dan toleransi yang lebih baik daripada generasi sebelumnya serta cenderung memanfaatkan teknologi dalam memperoleh informasi.

Tingkat pendidikan mempengaruhi pengetahuan seseorang, semakin tinggi tingkat pendidikan maka memiliki pengalaman dan wawasan lebih luas, yang akan berdampak kepada aspek kognitif seseorang ${ }^{20}$. Tingkat pendidikan juga akan mempengaruhi terbentuknya sikap dan perilaku seseorang. Penelitian mengungkapkan bahwa terdapat hubungan positif tingkat pendidikan dan status kesehatan. Semakin tinggi tingkat pendidikan akan semakin baik status kesehatanya. Upaya meningkatkan pendidikan dapat dilakukan remaja baik secara formal ataupun non formal ${ }^{21}$. Hasil penelitian menunjukkan bahwa 
mayoritas generasi milenial dengan pendidikan terakhir SMA lebih memilih menggunakan internet/Hp sebagai sumber informasi. Masyarakat dengan Pendidikan SMA memiliki perilaku konsumsi media internet yang sangat tinggi. Hal ini sesuai dengan karakteristik generasi milenial yang hidup pada perkembangan teknologi yang pesat, kurang suka membaca secara konvensional, lebih percaya informasi interaktif daripada searah dan lebih menyukai sesuatu hal yang instan karena dirasa lebih mudah dan praktis ${ }^{22}$. Penelitian yang dilakukan oleh Aulia yang membuktikan Social Category Theory yaitu bahwa tingkat pendidikan menjadi salahsatu faktor yang mempengaruhi perilaku konsumsi media ${ }^{23}$.

Frekuensi penggunaan internet menurut Pranata masyarakat Surabaya rata-rata mengakses internet melalui smartphone dengan durasi $>5 \mathrm{jam} / \mathrm{hari}^{24}$. Frekuensi penggunan internet semakin berkurang seiring bertambahnya usia. Masyarakat dengan usia $>30$ tahun rata-rata mengakses internet dengan durasi dibawah 5 jam per hari dan usia $>40$ tahun hanya mengakses internet dengan durasi kurang dari 3 jam per hari. Frekuensi penggunaan internet dapat mempengaruhi tingkat pengetahuan seseorang, semakin sering seseorang menggunakan internet maka akan semakin banyak informasi yang mungkin akan didapatkan. Penelitian oleh Kheilan mengungkapkan terdapat hubungan antara intensitas penggunaan internet dengan tingkat pengetahuan. Intensitas penggunaan internet yang berat (>10 jam seminggu) dapat mempengaruhi tingkat pengetahuan dan sikap kesehatan reproduksi remaja ${ }^{25}$

\section{Hasil Pendidikan Gizi Prakonsepsi Generasi Milenial}

Hasil perbedaan rata-rata berdasarkan uji Paired Sampe t-test (Tabel.2) menunjukkan bahwa terdapat peningkatan hasil pendidikan gizi yaitu skor pretest dan postest pada kelompok kontrol yang menggunakan media komunikasi online Whatsapp dan kelompok eksperimen yang menggunakan Zoom Cloud Meeting sehingga dapat diartikan bahwa penggunaan media komunikasi online Whatsapp dan Zoom Cloud Meeting dapat secara efektif digunakan untuk meningkatkan pengetahuan gizi prakonsepsi. Hal ini dikarenakan penggunaan media komunikasi online sebagai dalam kegiatan pendidikan tidak hanya terpaku dalam satu waktu dan ruang saja sehingga dapat meningkatkan mutu pembelajaran ${ }^{26}$. Penggunaan teknologi informasi dan telekomunikasi akan menghilangkan batasan ruang dan waktu dalam dunia pendidikan ${ }^{27}$. Berdasarkan penelitian yang dilakukan oleh Kuntarto menunjukkan bahwa kegiatan pendidikan secara daring dapat memberikan pengalaman baru yang lebih menantang daripada kegiatan pendidikan secara konvensional atau tatap muka ${ }^{28}$.

Secara Nyata tidak terdapat perbedaan hasil yang signifikan antara penggunaan kombinasi media pada kelompok eksperimen yang menggunakan Zoom Cloud Meeting dan kelompok kontrol yang menggunakan Whatsapp $(p=0,686)$, hasil perbedaan yang tidak signifikan ini karena kelebihan dan kekurangan yang dimiliki masing-masing media selain itu 
dapat disebabkan karena kondisi dan hambatan responden yang berbeda-beda diantaranya motivasi belajar, kondisi lingkungan dan kesehatan fisik sehingga dapat mempengaruhi hasil pendidikan ${ }^{29}$. Kendala teknis seperti jaringan internet yang tidak stabil dapat menjadi hambatan dalam kegiatan pendidikan secara daring. Berdasarkan penelitian yang dilakukan oleh Mustakim mengungkapkan bahwa kendala yang dihadapi peserta selama daring diantaranya jaringan internet yang tidak stabil $(66,7 \%)$, sulit fokus $(56,7 \%)$ dan aplikasi yang rumit $(10 \%)^{30}$.

Berdasarkan hasil penelitian media Whatsapp memiliki pengaruh yang lebih baik dalam peningkatan hasil pendidikan gizi prakonsepsi dibandingkan dengan Zoom Cloud Meeting, Whatsapp lebih disukai oleh peserta didik dibandingkan dengan Zoom Cloud Meeting dikarenakan penggunaan media Whatsapp lebih praktis dan mudah digunakan serta tidak terlalu banyak membutuhkan pulsa kuota ${ }^{30}$. Penelitian mengungkapkan hanya $44 \%$ siswa yang menilai Zoom Cloud Meeting efektif digunakan untuk kegiatan pembelajaran ${ }^{31}$.

Penggunaan Zoom Cloud Meeting dinilai tidak efektif dalam meningkatkan pengetahuan mahasiswa dengan penyebab kemungkinan jaringan yang tidak stabil dan penyampaian materi yang kurang jelas ${ }^{32}$. Penggunaan media komunikasi online sebagai alternatif dalam kegiatan pendidikan jarak jauh harus memperhatikan kecepatan dalam mengakses internet atau jaringan, keterbatasan bandwidth, biaya untuk akses internet, serta latar belakang pengetahuan yang menyangkut kesiapan dalam mengikuti pembelajaran ${ }^{33}$.

Microsoft Sway digunakan untuk membuat materi yang menarik dan presentatif serta dalam penggunannya dapat dikombinasikan dengan media komunikasi online baik Whatsapp ataupun Zoom Cloud Meeting sebagai strategi pendidikan yang lebih interaktif dan tidak membosankan. Berdasarkan penelitian menunjukkan siswa millenial lebih memilih pembelajaran berbasis website daripada pembelajaran konvensional dan terbukti pada hasil belajar menggunakan Microsoft Sway lebih tinggi daripada menggunakan handout ${ }^{34}$.

\section{SIMPULAN DAN SARAN}

penggunaan kombinasi media komunikasi online secara efektif dapat meningkatkan hasil pendidikan. Tidak terdapat perbedaan signifikan hasil pendidikan gizi generasi milenial pada penggunaan kedua kombinasi media komunikasi online, namun penggunaan kombinasi Microsoft Sway-Whatsapp dinilai memberikan hasil yang lebih baik karena dinilai praktis, mudah digunakan dan tidak membutuhkan lebih banyak pulsa kuota dibandingkan dengan penggunaan kombinasi media Microsoft Sway-Zoom Cloud Meeting

Penggunaan media komunikasi online dalam pendidikan sebaiknya mempertimbangkan kemampuan media, jaringan internet, dan biaya akses agar tujuan tecapai secara optimal Perlu adanya penelitian lebih lanjut penggunaan media komunikasi online secara bertahap sehingga dapat berpengaruh pada perubahan sikap dan perilaku gizi. 


\section{DAFTAR PUSTAKA}

1. Ali H, Purwandi L. Indonesia 2020: The Urban Middle Class Millenials. Alvara Res Cent. 2016;1-32.

2. Paratmanitya $\mathrm{Y}$, Hadi H. Citra tubuh, asupan makan, dan status gizi wanita usia subur pranikah. 2012;8(3):126-34.

3. Dinkes Kota Surabaya. Buku Profil Kesehatan Kota Surabaya Tahun 2017. Surabaya. Dinas Kesehatan Kota Surabaya; 2017.

4. Notoatmodjo S. Promosi Kesehatan dan Perilaku Kesehatan. Jakarta: PT Rineka Cipta; 2012.

5. Kegg D, Guilmette A, Mandich L, Fisher E. Microsoft Office 365 Administration Inside Out. United States of America: Pearson Education Inc; 2017.

6. Widiastuti L\&, Wiyarno Y. Pengembangan Media Pembelajaran Berbasis Sway Pada Mata Pelajaran Teknologi Informasi Dan Komunikasi. TEKNODIK J [Internet]. 2019;23(4):163-74. Available from: https://jurnalteknodik.kemdikbud.go.id/index.php/jurnalteknodik/article/view/588/434

7. Almuntaqo A. Pengaruh Pemanfaatan Microsoft Sway Terhadap Peningkatan Kolaborasi Dalam Kegiatan Pembelajaran Pada Mata Kuliah Media Televisi dan Video: Kuasi Eksperimen Terhadap Mahasiswa Program Studi Teknologi Pendidikan UPI [Internet]. Universitas Pendidikan Indonesia; 2017. Available from: http://repository.upi.edu/id/eprint/29671

8. Rahmadi IF. Whatsapp group for teaching and learning in indonesian higher education what's up? Int J Interact Mob Technol. 2020;14(13):150-60.

9. Suryadi E, Ginanjar MH, Priyatna M. PENGARUH PENGGUNAAN MEDIA SOSIAL WHATSAPP TERHADAP KEAKTIFAN SISWA PADA MATA PELAJARAN EKONOMI BISNIS KELAS X SMK NEGERI 2 BOYOLANGU TAHUN AJARAN 2018/2019. J Pendidik Islam [Internet]. 2019;12(2). Available from: http://journal2.um.ac.id/index.php/jpe/index

10. Larasati W, Dkk. Efektivitas Pemanfaatan Aplikasi WhatsApp sebagai Sarana Diskusi Pembelajaran Pada Mahasiswa. 2013.

11. Sulistyaning K, Pratama H. Pengaruh Penggunaan WhatsApp Messenger Sebagai Mobile Learning Terintegrasi Metode Group Investigation Terhadap Kemampuan Berpikir Kritis. JUPITER (Jurnal Pendidik Tek Elektro). 2017;2(September):33-8.

12. Bansal T, Joshi D. A Study of Students' Experiences of Mobile Learning. 2014;14(4).

13. Ibtidaiyah JM. Muallimuna : jurnal madrasah ibtidaiyah. 2020;29:74-84.

14. Suardi. The Effectiveness of Using the ZOOM Cloud Meetings Application in the Learning Process. In: Proceeding of The International Conference on Science and Advanced Technology (ICSAT). 2020. p. 590-602. 
15. Iskandar. Banyak Celah Keamanan Ini Kelebihan dan Kekurangan Zoom [Internet]. 2020. Available from: https://www.liputan6.com/tekno/read/4229930/banyak-celahkeamanan-inikelebihan-dan-kekurangan-zoom.

16. Falahudin I. Pemanfaatan Media dalam Pembelajaran. 2014;(4):104-17.

17. Dahlan MS. Statistik Untuk Kedokteran dan Kesehatan. Jakarta: Salemba Medika; 2016.

18. Statistik BP. Statistik Pemuda Indonesia 2017 [Internet]. Katalog BP. Jakarta: Badan Pusat Statistik; 2017. Available from: https://www.bps.go.id/

19. Taufik A. Analisis Karakter Peserta Didik. el-Ghiroh [Internet]. 2019;XVI(01). Available from:

https://www.google.com/url?sa=t\&rct=j\&q=\&esrc=s\&source=web\&cd=\&cad=rja\&uact $=$ 8\&ved=2ahUKEwiKhP3Ph53xAhUWbnOKHWfbD4sQFjAEegQIFRAE\&url=https\%3A \%2F\%2Fmedia.neliti.com\%2Fmedia\%2Fpublications\%2F294823-analisiskarakteristik-peserta-didik-08bec5c4.pdf\&usg=AOvVaw

20. Suwaryo PAW, Yuwono P. Faktor-faktor yang mempengaruhi tingkat pengetahuan masyarakat dalam mitigasi bencana alam tanah longsor. Urecol 6th. 2017;305-14.

21. Pradono J, Ning Sulistyowati. HUBUNGAN ANTARA TINGKAT PENDIDIKAN, PENGETAHUAN TENTANG KESEHATAN LINGKUNGAN, PERILAKU HIDUP SEHAT DENGAN STATUS KESEHATAN. Bul Penelit Sist Kesehat [Internet]. 2014;17(01):89-95.

https://www.google.com/url?sa=t\&rct=j\&q=\&esrc=s\&source=web\&cd=\&cad=rja\&uact= 8\&ved=2ahUKEwjHg9D5nebvAhWBXCsKHVvdA3kQFjACegQIBBAD\&url=https\%3A \%2F\%2Fmedia.neliti.com\%2Fmedia\%2Fpublications\%2F20885-ID-correlationbetween-education-level-knowledge-of-environme

22. Kusmana D. Kepemimpinan ideal pada era generasi milenial. J Manaj Pemerintah [Internet]. 2018;10(1):73-84. Available from: https://www.google.com/url?sa=t\&rct=j\&q=\&esrc=s\&source=web\&cd=\&ved=2ahUKE wilOY-

OyObvAhXLQ30KHYUmDbYQFjAlegQIChAD\&url=http\%3A\%2F\%2Fejournal.ipdn.ac. id\%2FJTP\%2Farticle\%2Fdownload\%2F413\%2F243\&usg=AOvVaw3XxmcMtVuWXO qWPRC1dYHj

23. Nur A. Pengaruh Usia, Tingkat Pendidikan dan Jenis Kelamin terhadap Perilaku Konsumsi Media. Universitas Diponegoro; 2014.

24. Pranata. Surabayan Digital Native [Internet]. 2014. Available from: https://www.elance.com/samples/infograp\%0Ahic-surabayan-digitalnative\%02infographics-photoshop\%02research/122535276/

25. Syevira $\mathrm{K}$, Ismangoen $\mathrm{H}$, Mumtihana Muchlis. Hubungan Intensitas Penggunaan 
Internet dengan Tingkat Pengetahuan dan Sikap Kesehatan Reproduksi Remaja di Diploma III Kluster IImu Pengetahuan Sosial (IPS) Sekolah Vokasi Universitas Gadjah Mada Tahun 2015. Univ Gadjah Mada [Internet]. 2015; Available from: http://etd.repository.ugm.ac.id/penelitian/detail/91173

26. Nadziroh F. Analisa Efektifitas Sistem Pembelajaran. J ILMU Komput DAN DESAIN Komun Vis. 2017;2(1):1-14.

27. Hartanto W. Penggunaan E-Learning Sebagai Media Pembelajaran. J Pendidik Ekon. 2016;10(1):1-18.

28. Kuntarto E. Keefektifan Model Pembelajaran Daring Dalam Perkuliahan Bahasa Indonesia di Perguruan tinggi. J Indones Lang Educ Lit [Internet]. 2017;3(1):53-65. Available from: https://www.syekhnurjati.ac.id/jurnal/index.php/jeill/article/view/1820

29. Riyani Y. Faktor-faktor yang Mempengaruhi Prestasi Belajar Mahasiswa. J EKSOS [Internet]. 2012;8:19-25. Available from: http://repository.polnep.ac.id/xmlui/bits\%0Atream/handle/123456789/354/03-YANI $\% 0 A R$.pdf?sequence $=1 \% 0 \mathrm{D}$

30. Mustakim. EFEKTIVITAS PEMBELAJARAN DARING MENGGUNAKAN MEDIA ONLINE SELAMA PANDEMI COVID-19 PADA MATA PELAJARAN MATEMATIKA. J Islam Educ. 2020;2(1):1-12.

31. Laili RN. The Use of Zoom Meeting for Distance Learning in Teaching English to Nursing Students during Covid-19 Pandemic. In 2020. p. 17-8.

32. Rahmatia, Syahira, Sajaril AE. PRESEPSI SISWA DAN GURU TERHADAP PEMBELAJARAN DARING DI SMA YAPIS MANOKWARI KELAS X. Visipena. 2020;11(2):334-51.

33. Putranti N. CARA MEMBUAT MEDIA PEMBELAJARAN ONLINE. 2013;2(2):139-47.

34. Harefa N, Indonesia UK, Sormin E, Indonesia UK, Sanga L, Purba L, et al. The difference of students' learning outcomes with project based learning using handout and sway Microsoft 365. J Pendidik Kim. 2019;11(2):24-30. 